\title{
Lumbar position sense and the risk of low back injuries in college athletes: a prospective cohort study Sheri P Silfies ${ }^{1}$, Jacek Cholewicki², N Peter Reeves ${ }^{2}$ and Hunter S Greene ${ }^{3}$
}

\begin{abstract}
Address: ${ }^{1}$ Rehabilitation Sciences Research Laboratory, Drexel University, Philadelphia, PA, USA, ${ }^{2}$ Biomechanics Research Laboratory, Department of Orthopaedics and Rehabilitation and Department of Biomedical Engineering, Yale University School of Medicine, New Haven, CT 06520, USA and ${ }^{3}$ Northern California Orthopedic Centers, Carmichael, CA 95608, USA
\end{abstract}

Email: Sheri P Silfies - silfies@drexel.edu; Jacek Cholewicki* - cholewic@msu.edu; N Peter Reeves - reevesn@msu.edu; Hunter S Greene - yaleortho@yahoo.com

* Corresponding author

Published: 31 December 2007

BMC Musculoskeletal Disorders 2007, 8:129 doi:10.1186/147|-2474-8-129

This article is available from: http://www.biomedcentral.com/I47I-2474/8/12

(c) 2007 Silfies et al; licensee BioMed Central Ltd.

This is an Open Access article distributed under the terms of the Creative Commons Attribution License (http://creativecommons.org/licenses/by/2.0), which permits unrestricted use, distribution, and reproduction in any medium, provided the original work is properly cited.
Received: 24 June 2007

Accepted: 31 December 2007

\begin{abstract}
Background: Impaired proprioception in the lumbar spine has often been reported in people with low back pain. However, no prospective studies exist to assert the cause and effect of this association. We hypothesized that athletes with a history of low back injury (LBI) would demonstrate poorer lumbar position sense (PS) than athletes without a history of LBI, and that this deficit would be a risk factor for future LBI.
\end{abstract}

Methods: This was a prospective cohort study with 2-3 year follow-up. Lumbar spine PS in the transverse plane was evaluated in 292 athletes using three tests: 1) passive and 2) active trunk repositioning, and 3) motion perception threshold. Mean absolute (accuracy) and variable (precision) errors were computed.

Results: There were no significant differences in the repositioning errors or motion perception threshold between athletes with and without a history of LBI or between those who did and did not get injured during the follow-up. Active trunk repositioning resulted in smaller errors than passive repositioning $\left(1.6^{\circ} \pm 0.8^{\circ}\right)$ versus $\left.2.1^{\circ} \pm 1.0^{\circ}\right)$ and $1.7^{\circ} \pm 0.8^{\circ}$ ) versus $2.3^{\circ} \pm 1.1^{\circ}$ ) for the absolute and relative errors, respectively).

Conclusion: Poor trunk PS in transverse plane is not associated with LBI in athletes, nor does it appear that poor trunk PS predisposes athletes to LBI.

\section{Background}

Intact proprioception is essential for movement control [1-3]. In the spine, proprioceptive information is provided by structures present in the spinal ligaments, facet joints, intervertebral discs [4-6], and paraspinal muscles $[7,8]$. Muscle spindle density is high in deep paraspinal rotators, which are small muscles spanning one or two segments of the spine [9]. It is believed that the spindles in these muscles act as kinesthetic sensors that monitor trunk position and movement. It is these muscle receptors that are more likely responsible for information in the midrange of trunk motions $[8,10]$. While joint receptors cannot be discounted, these structures are thought to provide more input toward the end range of joint positions [10]. However, altered joint afferent information can alter muscle activation [11]. Consequently proprioceptive information from both muscle and joint receptors may be an important aspect of trunk control of motion. Since the 
overwhelming majority of low back injuries (LBI) in athletes are classified as soft tissue injury, the mechanoreceptors embedded in these tissues could be involved [12-14].

Proprioceptive impairments, reflected by poor joint position sense (PS), have been identified in numerous soft tissue injuries commonly suffered by athletes: anterior cruciate ligament deficiency $[15,16]$, ankle sprains [17], glenohumeral instability $[18,19]$, neck injury $[20,21]$ and low back pain (LBP) $[8,22-27]$. However, in the LBP literature, the evidence regarding the presence of proprioceptive impairments is not unanimous. Newcomer et al. (2000) [28] reported significantly larger repositioning error in patients with LBP in trunk flexion and significantly lower error in trunk extension when compared to a control group. Field et al. (1991) [29] found less variability in repositioning error in their LBP group and Parkhurst et al. found no correlation between directly measured proprioceptive variables and LBI, but instead reported its association with the asymmetry indices derived from these variables [30]. Finally, several studies demonstrated no proprioceptive impairments in individuals reporting LBP or injury [31-34]. Differences in test conditions (body position, planes of motion, whether or not vestibular system is involved, lower body constraint), and subject characteristics could explain some of the divergent results in the literature.

Despite the above uncertainties, widely reported deficits in postural control [35-39] and altered patterns of muscle response to sudden trunk loading [40-42] among patients with LBP are hypothesized to be, at least in part, the result of injury to mechanoreceptors embedded in the soft tissues surrounding the lumbar spine. However, an alternative hypothesis would be that impaired spinal proprioception is a pre-existing risk factor that predisposes individuals to LBI.

The aims of this prospective study were to 1) examine whether differences in trunk PS exist between individuals with and without a history of LBI, and 2) determine if impairment in trunk PS results from injury or alternatively predisposes athletes to future LBI. Knowledge gained regarding trunk proprioceptive deficits would assist in developing targeted interventions for athletes. We hypothesized that athletes with a history of LBI would demonstrate less accurate and precise trunk repositioning and higher motion perception thresholds. Additionally, athletes with poor trunk PS would have a higher risk of sustaining a LBI than athletes with more accurate and precise trunk PS.

\section{Methods Subjects}

Two hundred and ninety two Yale University athletes from 22 sports were recruited to participate in this study. The athletes represented a homogenous group with respect to age, general health and fitness level. All but 4 subjects were varsity athletes. Two of the 4 subjects participated in club level sports (rugby, martial arts), 1 in weight lifting and 1 was a nationally ranked badminton player. All provided written informed consent as approved by the Yale University's Human Investigations Committee. Prior to experimental testing, subjects completed a questionnaire containing personal data (age, height, weight, sport, years of participation at varsity level, past medical history), a $10-\mathrm{cm}$ visual analog pain scale (0-100) [43], Roland Morris Disability Scale (0-24) [44], and additional questions regarding any previous LBI and recovery.

Incidence of LBI was recorded during a 2-3 years followup period. It varied slightly for each athlete due to the time elapsed between the testing session and graduation from college. During the follow-up, participating athletes received regular electronic mailings to ascertain their LBI status and to insure a high capture rate of LBI. Our operational definition of an injury was any LBP that caused the athlete to seek medical attention (physician, athletic trainer, or physical therapist) and to miss at least 3 days of participating in their sport or training routine. All inclusion and exclusion criteria were based on self-reported data, which were verified with training room and team physician records.

\section{Procedures}

Lumbar spine PS in the transverse was evaluated using a specially built apparatus similar to the one used by Taimela et al. [25] (Fig. 1). It was designed to produce passive motion of the lumbar spine in the transverse plane. The resolution of the angular measurement of this apparatus was less than $0.01^{\circ}$ and the accuracy obtained from the calibration curve was $0.35^{\circ}$. Subjects were positioned in the apparatus so that the vertical pivot axis coincided with the imaginary line drawn between the apex of the iliac crest and greater trochanter. Their arms were crossed with hands resting on opposite shoulders to eliminate cueing of lower body movement. The subject's legs rested on the feet support, creating a $90^{\circ}$ knee angle. The seat was driven by a stepper motor at a steady slow rate to minimize tactile cueing. The contribution of the vestibular system was eliminated by securing the upper body to the backrest with a 4-point seatbelt. The subjects performed all trials with closed eyes. Auditory cues produced by the stepper motor were masked by background noise from a buzzer. 


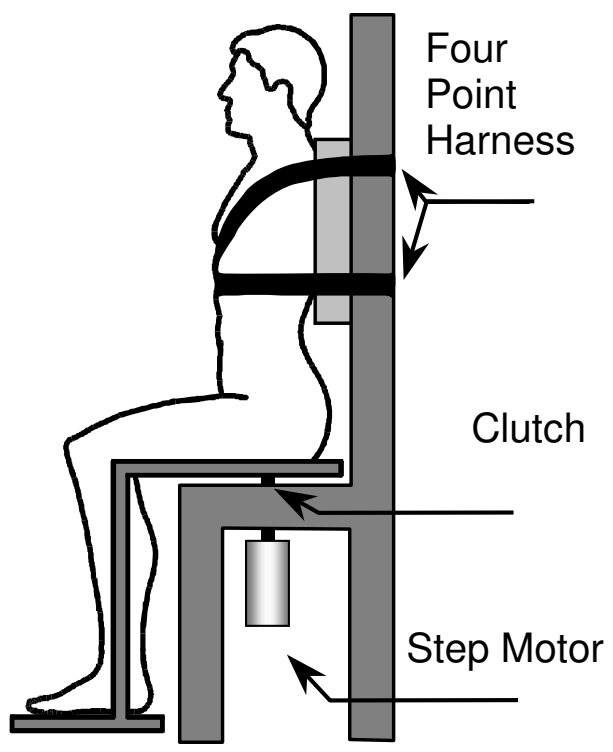

\section{Figure I}

Apparatus. A subject positioned in the trunk position sense testing apparatus, such that a pivot axis coincided with the imaginary line drawn between the apex of the iliac crest and greater trochanter. The upper body was fixed to the backrest with a 4-point harness.

Three tests were performed: 1 ) passive and 2) active repositioning to neutral (zero degrees of trunk rotation) and 3) motion perception threshold (MPT). In all tests, subjects were given 2 practice trials in each direction and verbal feedback of their error. This was followed by 10 trials randomized for direction ( 5 trials in each direction). Subjects stayed in the apparatus between the tests and were coached not to change their seated position. None of the athletes reported any discomfort during testing.

The seat drive could be disengaged from the motor with a clutch to allow both passive (motor driven return) and active trunk repositioning tests. In either case, subjects were initially rotated $20^{\circ}$ away from the neutral spine posture at $2.2^{\circ} / \mathrm{sec}$ and briefly held in that position $(2.0$ $\mathrm{sec}$ ). In the passive test, subjects were then slowly rotated towards the original position by the stepper motor at $1.0^{\circ} / \mathrm{sec}[30]$. In the active test, subjects rotated themselves back to neutral after the clutch was disengaged from the motor drive. In both tests, subjects recorded their perceived neutral position by pressing the hand held switch, which also stopped the apparatus.

The MPT test measured the smallest amount of rotation a subject could perceive. Starting in the neutral (zero) position, subjects were rotated either clockwise or counterclockwise at a constant rate of $0.1 \%$ sec. As soon as the motion was perceived, subjects stopped the rotation by pressing the switch and immediately stated the direction of movement. Subjects were returned to the neutral position following each trial. To avoid undesirable score variations from combining the MPT with directional motion perception, in only those trials, in which subjects correctly identified the direction of motion, was the degree of rotation recorded [30]. Testing continued until 5 data points were recorded for each direction of rotation.

\section{Data Analysis}

Repositioning accuracy was the difference between neutral $\left(0^{\circ}\right)$ and the actual position the subject indicated as neutral. Using the mean absolute repositioning error, we found no significant differences between left and right rotations, so the data were combined to create ten measurements for each test. Of the 10 measurements, the 2 highest errors were eliminated to reduce variability and the mean of 8 measures was used for analysis. Two types of error were calculated for active and passive repositioning: absolute error ( $\mathrm{AE}$ ) and variable error (VE). $\mathrm{AE}$ is a measure of accuracy and represents the mean absolute value of the deviation between subjects' perceived neutral position and the actual neutral position without regard for direction of the error. The VE is a measure of precision and represents the average deviation of each trial from subjects' mean score. The MPT was the smallest amount of rotation from the neutral position that was perceived by the subject.

To address both hypotheses, a MANOVA was used for 2 repositioning parameters ( $\mathrm{AE}$ and $\mathrm{VE}$ ) with 3 betweensubject factors 1) history versus no history of LBI, 2) injury versus no injury during the follow-up period, 3) gender, and 1 within-subject factor of test mode (passive versus active). When the MANOVA demonstrated a significant effect, univariate post-hoc tests were employed. A 3-way ANOVA was performed to determine group differences for MPT with 1) history versus no history of LBI, 2) injury versus no injury during the follow-up period, and 3) gender as the 3 factors. All statistical analyses were performed in Minitab (Minitab Inc., State College, PA).

All measures of trunk PS (active and passive $\mathrm{AE}, \mathrm{VE}$, and MPT) were examined for within-session repeatability using intra-class correlation coefficients (ICC) model (2, k) and standard error of measurement (SEM) [45]. For this purpose, the averages of the first five and the last five trials served as the test-retest values for all athletes.

\section{Results}

Our results reflected 292 college athletes who could be undoubtedly classified as injured or not injured based on the availability of records and our definition of injury. Their characteristics are presented in Table 1. At the start 
Table I: Characteristics of athletes with no history of low back injury (No Hx LBI) and with a history of low back injury (Hx LBI) at the start of study, and the athletes who sustained injury during the follow-up period (LBI during follow-up)*.

\begin{tabular}{|c|c|c|c|c|c|c|}
\hline \multirow[b]{3}{*}{ Gender } & \multicolumn{4}{|c|}{ Injury Status at the Start of Study $(n=292)$} & \multirow{2}{*}{\multicolumn{2}{|c|}{$\begin{array}{c}\text { Injured During Follow-up } \\
\qquad \mathrm{LBI}(\mathrm{n}=3 \mathrm{I})\end{array}$}} \\
\hline & \multicolumn{2}{|c|}{ No Hx LBI $(n=232)$} & \multicolumn{2}{|c|}{$\mathrm{H} \times \mathrm{LBI}(\mathrm{n}=60)$} & & \\
\hline & $\mathrm{F}$ & M & $\mathrm{F}$ & M & $\mathrm{F}$ & M \\
\hline Number (n) & 115 & 117 & 33 & 27 & 16 & 15 \\
\hline Age (yrs) & $19.4(1.0)$ & $19.3(1.3)$ & $19.4(1.0)$ & $19.9(3.0)$ & $19.3(0.9)$ & $19.6(1.2)$ \\
\hline Height $(\mathrm{cm})$ & $169(7)$ & $183(8)$ & $172(8)$ & $183(7)$ & $174(7)$ & $186(7)$ \\
\hline Weight (kg) & $64.9(8.6)$ & $79.7(11.5)$ & $67.4(8.1)$ & $82.7(15.3)$ & $69.5(8.3)$ & $88.8(14.9)$ \\
\hline Time Post Injury (months) $\dagger$ & -- & -- & $24.0(22.6)$ & $21.0(17.5)$ & $--\#$ & $--\#$ \\
\hline VAS $(0-100) \ddagger$ & -- & -- & $69.0(14.1)$ & $57.5(22.2)$ & $--\#$ & $--\#$ \\
\hline RMQ $(0-24) \S$ & -- & -- & $5.5(3.8)$ & $5.2(5.2)$ & $--\#$ & $--\#$ \\
\hline
\end{tabular}

*Data represent means (SD).

†Time Post Injury = number of months between the last $\mathrm{LBI}$ and testing.

$\ddagger V A S=$ visual analog pain scale $(0-100)$ at time of injury (higher score means greater amount of pain).

$\S \mathrm{RMQ}=$ Roland Morris Disability Questionnaire (0-24) at time of injury (higher score means greater level of disability).

\#Subjects were not re-tested during the follow-up period.

of the study, 60 athletes (21\%) had a history of LBI within the last five years. Majority of them $(43(72 \%))$ sustained only a single LBI episode whilst the remainder had multiple episodes. During the follow-up period, 31 athletes $(11 \%)$ became injured (Table 1). Of these, 12 athletes $(39 \%)$ had a history of LBI. The athletes injured during follow-up were significantly $(\mathrm{p}<0.01)$ taller $(1.80(0.09)$ $\mathrm{m}$ vs. $1.76(0.10) \mathrm{m})$ and heavier $(78.9(15.3) \mathrm{kg}$ vs. $72.0(12.4) \mathrm{kg}$ ) than the uninjured athletes. The effects of history and subject characteristics on LBI were addressed in a previous publication [46]. The current report focuses solely on trunk PS data.

All data met assumptions of normality (Anderson-Darling test, Minitab, Inc.). The initial MANOVA returned no significant differences in trunk repositioning error in the transverse plane between the athletes with and without a history of LBI $(p=0.25)$ or between those who did and did not sustain a LBI during the follow-up period ( $\mathrm{p}=$ 0.63 ) (Table 2). However, significant effects of test mode (passive or active) $(\mathrm{p}<0.01)$ and gender $(\mathrm{p}=0.04)$ were present. The post-hoc univariate analyses revealed that the athletes were significantly more accurate $(\mathrm{AE}, \mathrm{p}<0.01)$ and precise (VE, $\mathrm{p}<0.01)$ in the active trunk repositioning tests as compared to the passive tests (Figure 2). Males were slightly $\left(0.15^{\circ}\right)$, but significantly less accurate $(\mathrm{AE}, \mathrm{p}$ $=0.02)$ and less precise $(\mathrm{VE}, \mathrm{p}=0.01)$ than females (Figure 3).

There were no significant effects of any of the factors on MPT. On average, all athletes perceived their trunk rotation at $1.1^{\circ}\left(\mathrm{SD}=1.0^{\circ}\right)$.

The within-session reproducibility of the active and passive repositioning tests was good $(0.47<$ ICC $<0.61$, $0.57^{\circ}<\mathrm{SEM}<0.73^{\circ}$, Table 3 ). The reproducibility of MPT was excellent with ICC $=0.89$ and SEM $=0.34^{\circ}$ (Table 3 ).

\section{Discussion}

There is inconsistency in the literature with regards to impairment in trunk PS and LBP. Some studies have found impairment $[8,22-27]$, whilst others have not [3134]. Because of these inconsistencies, it was not possible to state objectively whether LBP was associated with impairment in trunk PS. To address this problem, we designed a large prospective study with a homogenous subject population using a similar protocol to that of Taimela, Leinonen, and colleagues [25-27]. This protocol

Table 2: Average (AE) and variable (VE) trunk repositioning errors in the active and passive tests for athletes with or without history of low back injury (No/Hx LBI), and for athletes who did or did not sustained injury during the follow-up period (No/LBI)*.

\begin{tabular}{lcccccccc}
\hline & \multicolumn{2}{c}{ Active AE } & \multicolumn{2}{c}{ Passive AE } & & Active VE & & Passive VE \\
\cline { 2 - 8 } & No LBI & LBI & No LBI & LBI & No LBI & LBI & No LBI & LBI \\
\hline No Hx LBI & $1.6(0.8)$ & $1.7(0.7)$ & $2.1(1.0)$ & $2.1(0.7)$ & $1.7(0.8)$ & $1.8(0.7)$ & $2.3(1.0)$ & $2.3(0.8)$ \\
Hx LBI & $1.6(0.6)$ & $1.4(0.7)$ & $2.2(1.1)$ & $2.2(1.4)$ & $1.7(0.6)$ & $1.5(0.8)$ & $2.4(1.1)$ & $2.3(1.3)$ \\
\hline
\end{tabular}

*Data represent means (SD). 


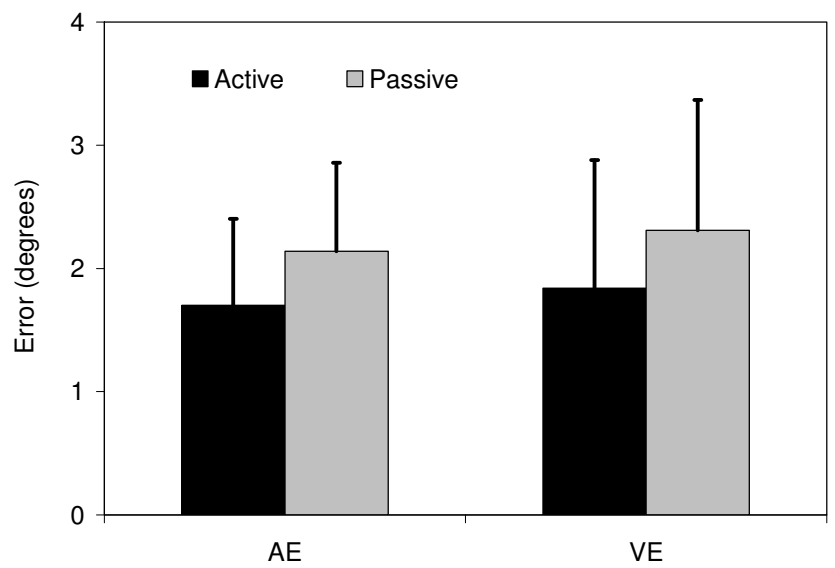

Figure 2

Significant differences existed between the active and passive measurements of trunk repositioning errors $(p<0.0 \mathrm{I})$.

These differences were present in both average $(A E)$ and variable (VE) errors. Data represents means with standard deviation bars (pooled across all trials and test modes).

has the advantage in that it isolates proprioception to trunk sensory receptors, while other inputs from lower extremities, vision, and the vestibular system are removed. Given the results of this study, we would conclude that impaired trunk PS is not associated with LBP. It appears that the majority of back injuries in athletes do not involve significant disruption of trunk PS, nor does it appear that poor trunk PS predisposes athletes to LBI. In comparison to previous studies, our results are strengthened by the use of a large homogenous subject group,

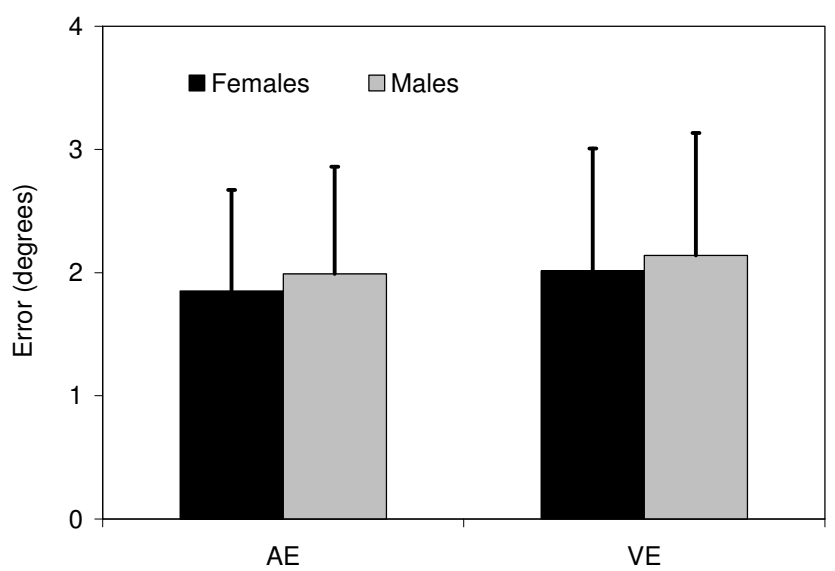

Figure 3

Significant differences existed in trunk repositioning accuracy between males and females $(P=0.04)$. These differences were present in both average $(A E)$ and variable $(V E)$ errors. Data represents means with standard deviation bars (pooled across all subjects and trials).
Table 3: Within-session repeatability* of average (AE) and variable (VE) trunk repositioning errors in the active and passive tests and motion perception threshold (MPT) measures.

\begin{tabular}{lcc}
\hline & ICC (2, k) & SEM (deg) \\
\hline Active AE & 0.61 & 0.57 \\
Passive AE & 0.58 & 0.73 \\
Active VE & 0.47 & 0.58 \\
Passive VE & 0.59 & 0.69 \\
MPT & 0.89 & 0.34 \\
\hline
\end{tabular}

*Repeatability was quantified with intra-class correlation coefficient (ICC) and standard error of measurement in degrees (SEM).

measurement of several aspects of trunk proprioception, isolation of the trunk from lower extremity input and standardization of the range of movement of each subject around the neutral trunk position.

It is possible that our athlete population differs from the general population used in others studies with positive findings. Perhaps, factors such as age or fitness levels can account for the differences between the LBP and healthy controls. Proprioception declines with age $[47,48]$ and more fit individuals may have more accurate joint PS. This notion has been supported by research demonstrating better knee MPT in trained gymnasts versus healthy non gymnasts [49].

It is also possible that other planes of motion can be affected more by LBP than the transverse plane used in our study. However, it should be noted that a number of the positive studies documented impairment in this plane [25-27]. So it would be expected that if impairment exists, it would also be found in the transverse plane of motion.

If impairment in trunk PS was strongly related to LBP, the findings in the literature would be more consistent. O'Sullivan et al.[23] suggested that the non-homogeneity of patients in terms of their specific pathologies may be responsible for the conflicting findings in research on trunk PS and LBP. The majority of injuries suffered by the athletes in our study were classified by health professionals in general terms as sprains or strains, and we did not attempt to diagnose these injuries further. It could be that impairment in trunk PS is specific to a particular patient population and/or pathology. This is still a possibility that needs to be investigated further.

It is unlikely that measurement limitations in our study could be responsible for the lack of differences in trunk PS between the athletes with and without a history of LBI or those who did and did not get injured during the followup. Our measurement errors (SEM) varied from $0.34^{\circ}$ to $0.73^{\circ}$ for the various test modes, and are in line with similar studies reporting diminished trunk PS in the LBP pop- 
ulations $[25,30]$. The magnitude of repositioning errors and the MPT obtained in the present study was also compatible with control groups in previous research (between $0.8^{\circ}$ and $\left.1.6^{\circ}\right)[25,30]$. More importantly, however, since our method was sufficiently sensitive to detect the differences in trunk repositioning accuracy between the active and passive testing modes (to be discussed shortly), it is likely that our data truly reflect the lack of impairment in athletes with a history of LBI. With similar confidence in our prospective study design, we can also reject the hypothesis that impaired trunk PS is a risk factor for sustaining a LBI in athletes.

Results from our study suggest differences between active and passive testing modes. Similarly to most of the relevant literature [50-56], we too found that active trunk repositioning resulted in smaller errors than passive trunk repositioning. It is generally agreed that afferent input from muscle spindle, encoding information tied to active movement, is in part responsible for a more accurate and precise joint PS in the active testing mode. However, other mechanisms, such as central corollary discharge, can be also used in a feedforward mechanism to assist in the reproduction of joint position [54].

Data from the current study revealed small gender differences in favor of females having slightly more accurate and precise trunk PS. However, clinical significance of differences in trunk repositioning error smaller than $0.15^{\circ}$ is probably negligible. Thus, these findings should be interpreted more in line with other literature, which reported no gender differences $[25,57]$.

\section{Conclusion}

Many athletic rehabilitation programs emphasize proprioception training as it is believed that impaired joint PS may be a major risk factor for recurrent injuries [2,58]. While it is true that a history of LBI was the single best predictor of future LBI in athletes [14], based on our data, the mechanism mediating such injuries is not likely an impairment in trunk PS. Even in the present study, the athletes with a history of LBI had a 3-times greater risk of sustaining a LBI during the follow-up [46], but their trunk PS was not different from the athletes who had no history of LBI or those who did not sustain a LBI during the follow-up. If impairments in trunk PS exist during acute stages of LBI, they appear to recover relatively rapidly and do not constitute a risk factor for recurrent LBI.

\section{Competing interests}

The author(s) declare that they have no competing interests.

\section{Authors' contributions}

All of the authors were involved with data collection, analysis, interpretation of results, and manuscript preparation. In addition, JC designed the study and secured funding. All authors read and approved the final manuscript.

\section{Acknowledgements}

This study was made possible by the NIH Grant ROI AR46844 from the National Institute of Arthritis and Musculoskeletal and Skin Diseases.

\section{References}

I. Laskowski ER, Newcomer-Aney K, Smith J: Proprioception. Phys Med Rehabil Clin N Am 2000, I I:323-340.

2. Lephart SM, Pincivero DM, Giraldo JL, Fu FH: The role of proprioception in the management and rehabilitation of athletic injuries. Am J Sports Med 1997, 25:130-137.

3. Mergner T, Hlavacka F, Schweigart G: Interaction of vestibular and proprioceptive inputs. J Vestib Res 1993, 3:4I-57.

4. Bogduk N: The innervation of the lumbar spine. Spine 1983 , 8:286-293.

5. Holm S, Indahl A, Solomonow M: Sensorimotor control of the spine. J Electromyogr Kinesiol 2002, I 2:21 9-234.

6. Sjölander $\mathrm{P}$, Johansson H, Djupsjöbacka M: Spinal and supraspinal effects of activity in ligament afferents. J Electromyogr Kinesiol 2002, 12:167-176.

7. Brumagne S, Lysens R, Swinnen S, Verschueren S: Effect of paraspinal muscle vibration on position sense of the lumbosacral spine. Spine 1999, 24:|328-|33|.

8. Brumagne S, Cordo P, Lysens R, Verschueren S, Swinnen S: The role of paraspinal muscle spindles in lumbosacral position sense in individuals with and without low back pain. Spine 2000 , 25:989-994.

9. Nitz AJ, Peck D: Comparison of muscle spindle concentrations in large and small human epaxial muscles acting in parallel combinations. Am Surg 1986, 52:273-277.

10. Gandevia SC, McCloskey DI, Burke D: Kinaesthetic signals and muscle contraction. Trends Neurosci 1992, 15:62-65.

II. Solomonow M: Sensory - motor control of ligaments and associated neuromuscular disorders. J Electromyogr Kinesiol 2006, 16:549-567.

12. Keene JS, Albert MJ, Springer SL, Drummond DS, Clancy WG Jr.: Back injuries in college athletes. J Spinal Disord 1989, 2:190-195.

13. Nadler SF, Wu KD, Galski T, Feinberg JH: Low back pain in college athletes. A prospective study correlating lower extremity overuse or acquired ligamentous laxity with low back pain. Spine 1998, 23:828-833.

14. Greene HS, Cholewicki J, Galloway MT, Nguyen CV, Radebold A: A history of low back injury is a risk factor for recurrent back injuries in varsity athletes. Am J Sports Med 200I, 29:795-800.

15. Carter ND, Jenkinson TR, Wilson D, Jones DW, Torode AS: Joint position sense and rehabilitation in the anterior cruciate ligament deficient knee. BrJ Sports Med 1997, 31:209-2 I 2 .

16. Corrigan JP, Cashman WF, Brady MP: Proprioception in the cruciate deficient knee. J Bone Joint Surg Br 1992, 74:247-250.

17. Garn SN, Newton RA: Kinesthetic awareness in subjects with multiple ankle sprains. Phys Ther 1988, 68:1667-167|.

18. Warner JJ, Lephart S, Fu FH: Role of proprioception in pathoetiology of shoulder instability. Clin Orthop 1996:35-39.

19. Potzl W, Thorwesten L, Gotze C, Garmann S, Steinbeck J: Proprioception of the shoulder joint after surgical repair for Instability: a long-term follow-up study. Am J Sports Med 2004, 32:425-430.

20. Loudon JK, Ruhl M, Field E: Ability to reproduce head position after whiplash injury. Spine 1997, 22:865-868.

21. Revel M, Andre-Deshays C, Minguet M: Cervicocephalic kinesthetic sensibility in patients with cervical pain. Arch Phys Med Rehabil |991, 72:288-291.

22. Gill KP, Callaghan MJ: The measurement of lumbar proprioception in individuals with and without low back pain. Spine 1998, 23:37I-377. 
23. O'Sullivan PB, Burnett A, Floyd AN, Gadsdon K, Logiudice J, Miller D Quirke $\mathrm{H}$ : Lumbar repositioning deficit in a specific low back pain population. Spine 2003, 28: $1074-1079$.

24. Field $E$, Abdel-Moty $E$, Loudon J: The effect of back injury and load on ability to replicate a novel posture. Journal of Back \& Musculoskeletal Rehabilitation 1997, 8:199-207.

25. Taimela S, Kankaanpaa M, Luoto S: The effect of lumbar fatigue on the ability to sense a change in lumbar position. A controlled study. Spine 1999, 24: | 322-1327.

26. Leinonen V, Maatta S, Taimela S, Herno A, Kankaanpaa M, Partanen J, Kansanen M, Hanninen O, Airaksinen O: Impaired lumbar movement perception in association with postural stability and motor- and somatosensory-evoked potentials in lumbar spinal stenosis. Spine 2002, 27:975-983.

27. Leinonen V, Kankaanpaa M, Luukkonen M, Kansanen M, Hanninen O, Airaksinen $\mathrm{O}$, Taimela S: Lumbar paraspinal muscle function, perception of lumbar position, and postural control in discherniation-related back pain. Spine 2003, 28:842-848.

28. Newcomer KL, Laskowski ER, Yu B, Johnson JC, An KN: Differences in repositioning error among patients with low back pain compared with control subjects. Spine 2000 , 25:2488-2493

29. Field E, Abdel-Moty E, Khalil T, Asfour S: Postural proprioception in healthy and back-injured adults. Phys Ther 1991, 7I:SI04-SI05.

30. Parkhurst TM, Burnett $\mathrm{CN}$ : Injury and proprioception in the lower back. J Orthop Sports Phys Ther 1994, 19:282-295.

31. Koumantakis GA, Winstanley J, Oldham JA: Thoracolumbar proprioception in individuals with and without low back pain intratester reliability, clinical applicability, and validity. J Orthop Sports Phys Ther 2002, 32:327-335.

32. Lam SS, Jull G, Treleaven J: Lumbar spine kinesthesia in patients with low back pain. J Orthop Sports Phys Ther 1999, 29:294-299.

33. Descarreaux M, Blouin JS, Teasdale N: Repositioning accuracy and movement parameters in low back pain subjects and healthy control subjects. Eur Spine J 2005, I4:|85- |9|

34. Åsell M, Sjölander P, Kerschbaumer H, Djupsjöbacka M: Are lumbar repositioning errors larger among patients with chronic low back pain compared with asymptomatic subjects? Arch Phys Med Rehabil 2006, 87: I 170-1 176.

35. Radebold A, Cholewicki J, Polzhofer GK, Greene HS: Impaired postural control of the lumbar spine is associated with delayed muscle response times in patients with chronic idiopathic low back pain. Spine 200I, 26:724-730.

36. Luoto $\mathrm{S}$, Aalto $\mathrm{H}$, Taimela $\mathrm{S}$, Hurri H, Pyykko I, Alaranta $\mathrm{H}$ : Onefooted and externally disturbed two-footed postural control in patients with chronic low back pain and healthy control subjects. A controlled study with follow-up. Spine 1998 , 23:208I-2089.

37. Takala EP, Korhonen I, Viikari-Juntura E: Postural sway and stepping response among working population: Reproducibility, long-term stability, and associations with symptoms of the low back. Clin Biomech 1997, 12:429-437.

38. Mientjes MI, Frank JS: Balance in chronic low back pain patients compared to healthy people under various conditions in upright standing. Clin Biomech 1999, 14:710-7|6.

39. Byl NN, Sinnott PL: Variations in balance and body sway in middle-aged adults. Subjects with healthy backs compared with subjects with low-back dysfunction. Spine 1991, 16:325-330.

40. Hodges PW, Richardson CA: Delayed postural contraction of transversus abdominis in low back pain associated with movement of the lower limb. J Spinal Disord 1998, I I:46-56.

41. Radebold A, Cholewicki J, Panjabi MM, Patel TC: Muscle response pattern to sudden trunk loading in healthy individuals and in patients with chronic low back pain. Spine 2000, 25:947-954.

42. Cholewicki J, Polzhofer GK, Galloway MT, Greene HS, Shah RA, Radebold A: Neuromuscular function in athletes following recovery from an acute low back injury. J Orthop Sports Phys Ther 2002, 32:568-575.

43. Bijur PE, Silver W, Gallagher EJ: Reliability of the visual analog scale for measurement of acute pain. Acad Emerg Med 2001 , 8: II53-II57.

44. Roland M, Morris R: A study of the natural history of back pain. Part I: development of a reliable and sensitive measure of disability in low-back pain. Spine $1983,8:|4|-\mid 44$
45. Portney LG, Watkins MP: Foundations of Clinical Research: Applications to Practice. Norwalk, CT, Appleton \& Lange; 1993.

46. Cholewicki J, Silfies SP, Shah RA, Greene HS, Reeves NP, Alvi K, Goldberg B: Delayed trunk muscle reflex responses increase the risk of low back injuries. Spine 2005, 30:26 |4-2620.

47. Kaplan FS, Nixon JE, Reitz M, Rindfleish L, Tucker J: Age-related changes in proprioception and sensation of joint position. Acta Orthop Scand 1985, 56:72-74.

48. Skinner HB, Barrack RL, Cook SD: Age-related decline in proprioception. Clin Orthop 1984:208-2II.

49. Lephart SM, Giraldo JL, Borsa PA, Fu FH: Knee joint proprioception: a comparison between female intercollegiate gymnasts and controls. Knee Surg Sports Traumatol Arthrosc 1996, 4: I 21-124.

50. Taylor JL, McCloskey DI: Proprioceptive sensation in rotation of the trunk. Exp Brain Res 1990, 8 I:4I3-4I6.

5I. Lönn J, Crenshaw AG, Djupsjöbacka M, Pedersen J, Johansson $H$ : Position sense testing: influence of starting position and type of displacement. Arch Phys Med Rehabil 2000, 81:592-597.

52. Lönn J, Crenshaw AG, Djupsjöbacka M, Johansson H: Reliability of position sense testing assessed with a fully automated system. Clin Physiol 2000, 20:30-37.

53. Craske B, Crawshaw M: Shifts in kinesthesis through time and after active and passive movement. Percept Mot Skills 1975, 40:755-76I.

54. Laufer Y, Hocherman S, Dickstein R: Accuracy of reproducing hand position when using active compared with passive movement. Physiother Res Int 200I, 6:65-75.

55. Paillard J, Brouchon M: Active and passive movements in the calibration of position sense. In The neurophysiology of spatially oriented behavior Edited by: Freedman SE. Homewood, IL, The Dorsey Press; 1968:37-55.

56. Pickard CM, Sullivan PE, Allison GT, Singer KP: Is there a difference in hip joint position sense between young and older groups? J Gerontol A Biol Sci Med Sci 2003, 58:63 I-635.

57. Jakobs T, Miller JA, Schultz AB: Trunk position sense in the frontal plane. Exp Neurol 1985, 90: I29-I38.

58. Laskowski ER, Newcomer-Aney K, Smith J]: Refining rehabilitaiton with proprioception training: expediting return to play. Phys Sportsmed 1997, 25:89.

\section{Pre-publication history}

The pre-publication history for this paper can be accessed here:

http://www.biomedcentral.com/1471-2474/8/129/pre pub

Publish with BioMed Central and every scientist can read your work free of charge

"BioMed Central will be the most significant development for disseminating the results of biomedical research in our lifetime. "

Sir Paul Nurse, Cancer Research UK

Your research papers will be:

- available free of charge to the entire biomedical community

- peer reviewed and published immediately upon acceptance

- cited in PubMed and archived on PubMed Central

- yours - you keep the copyright
BioMedcentral 